\title{
How to motivate public security police effectively?
}

\author{
----Research on Public Security Organs in Hainan Province \\ Shanshan Zhou ${ }^{1, a,}$, Jingtao Mao, ${ }^{2, b}{ }^{*}$ and Yutong Peng ${ }^{2, c}$ \\ ${ }^{1}$ School of Management, Lanzhou University, Lanzhou City, Gansu Province \\ ${ }^{2}$ School of Politics and Public Administration, Hainan University, Haikou City, Hainan Province \\ a2268047548@qq.com, b604489364@qq.com, c 175990837@qq.com \\ *corresponding author
}

Keywords: civil servant’s motivating; empirical analysis; countermeasure

\begin{abstract}
Through the investigation of public security organs in HaiNan Province, 798 valid samples are extracted. Firstly, the research framework is briefly introduced, then the questionnaire is designed, and the data are analyzed descriptive and reliability. Then the principal component analysis is carried out on the dimension of the incentive, which is the most important index. Finally, the use of promotion incentives, the content of job incentives, material and spiritual incentives in three dimensions of the important indicators is to encourage civil servants and to put forward countermeasures and suggestions.
\end{abstract}

\section{Introduction}

Public security organs are armed criminal justice and administrative law enforcement team, the police as the exercise of national security management and criminal justice functions of the professional groups, heavy task, pressure.[1] In addition, the current public security organs at the grassroots level is generally inadequate, grass-roots police long-term overload work, physical and mental fatigue, which not only affect the effectiveness of work, but also affect the continuous development of public security work. Under such realistic conditions, how to play the role of incentives to fully mobilize the initiative of the police, enthusiasm, encourage the police is particularly important. The three dimensions selected in this paper are promotion incentives, job content incentives, material and spiritual incentives.

\section{Summary of Survey Studies}

\subsection{Questionnaire design and content}

The questionnaire answers the answers to each question as "very nonconforming, less consistent, indifferent, somewhat consistent, very consistent with" the five levels.

On the basis of the civil service law, this questionnaire starts from the following three types of incentives: one is the factor of promotion incentive which aims to job promotion, the second is the factor of content incentive aiming at the work content; the third is the material and the spirit incentives for the objective of material and spiritual incentives. The questionnaire designs are shown in table 1, table 2 and table 3.

Because some of the problems are recognized the degree of recognition of the problem, so the answer to the question using the Likert scale method. In addition, the questionnaire also contains personal basic information: age and position, these issues are mainly descriptive analysis of the sample.

\subsection{The organization and implementation of the survey}

The survey was conducted in July 2015 to June 2016. In the time of the issue of the questionnaire, in order to do as completely random sampling as possible, through several contacts 
with the Provincial Public Security Department of the Political Department staff of the staff to get the province's public security police roster, followed by the roster of staff randomly selected. When picked up in accordance with the order of the order, the leadership of every two people selected one, the police every five people to select questionnaires issued.

Table 1

\begin{tabular}{|c|c|}
\hline Problem number & Problem \\
\hline A1 & Master and control more resources \\
\hline A2 & Own ideas and ideas to be implemented \\
\hline A3 & Get more respect and recognition \\
\hline A4 & Get more network resources \\
\hline A5 & Ability to be improved \\
\hline A6 & Get more pay and benefits \\
\hline A7 & Get more training opportunities \\
\hline A8 & Easy to dominate others to reduce their work intensity \\
\hline A9 & Easy access to the new circle of communication \\
\hline A10 & Easy to solve some of the problems in life \\
\hline A11 & To achieve personal ideal \\
\hline
\end{tabular}

Source: The author draws on the questionnaire design

Table 2

\begin{tabular}{|c|c|}
\hline Problem number & Problem \\
\hline A12 & The job is more challenging \\
\hline A13 & Job more in line with their own professional \\
\hline A14 & Position more in line with their hobbies or expertise \\
\hline A15 & Posts are more fixed and simple \\
\hline A16 & The job is more busy \\
\hline A17 & Posts deal more often with people \\
\hline A18 & There are more field opportunities in the post \\
\hline A19 & Positions are more accessible to leadership \\
\hline A20 & Position more in line with personal character, conducive to play \\
\hline A21 & Thersonal values are more opportunities to learn \\
\hline A22 & Job easier to have their own skills \\
\hline A23 & Positions can enrich their own social experience \\
\hline A24 &
\end{tabular}

Source: The author draws on the questionnaire design

Table 3

\begin{tabular}{|c|c|}
\hline Problem number & Problem \\
\hline A25 & Gain the verbal praise of the leader \\
\hline A26 & Get a higher professional title or title \\
\hline A27 & Obtain the approval and approval of colleagues \\
\hline A28 & Get the praise of the work object \\
\hline A29 & Get a sense of satisfaction and a sense of accomplishment \\
\hline A30 & To prove to others that their ability to work very strong \\
\hline A31 & To avoid being looked down upon by colleagues \\
\hline A32 & Do not have the heart to see others busy and do nothing \\
\hline A33 & $\begin{array}{c}\text { Access to advanced individuals, outstanding civil servants and other } \\
\text { honorary titles }\end{array}$ \\
\hline A34 & Get bonus income \\
\hline A35 & Get more bonus income and material rewards \\
\hline
\end{tabular}

Source: The author draws on the questionnaire design

\subsection{A descriptive analysis of the questionnaire}

A total of 974 questionnaires were collected in this questionnaire, and the number of valid 
questionnaires was 798. Effective rate of $81.9 \%$. In this 798 effective questionnaires, the number of males was 728, accounting for $91.23 \%$ of the total number of women; the number of men surveyed in the sample more than women, gender distribution The number of males in public security organs accounts for the general law of the vast majority.

There are 90 people, accounting for $11.28 \%$ of the total number of candidates; with administrative rank treatment of non-leadership positions of 40 people, accounting for $5.01 \%$ of the total number of samples; ordinary police have 668 people, the total number of samples $83.71 \%$. In line with the public security organs of the number of ordinary police far more than the leadership or leadership level of non-leadership of the number of treatment.

\subsection{Data reliability analysis}

Reliability, also known as reliability, refers to the credibility of the questionnaire analysis and reliability analysis, used to detect the reliability and consistency of survey data. By using the SPSS software to analyze the reliability of the survey data, the Cronbach's Alpha value of this paper is 0.833 , so the reliability of the survey data is credible.

\subsection{Principal Component Analysis of Incentive Factors}

The validity of the test is carried out by KMO and Bartlett's test. KMO is 0.865, indicating that the original variable is suitable for factor analysis. Bartlett's spherical degree test Sig (significance level) is 0.000 , far less than the maximum 0.05 , indicating that there is a correlation between the variables. So for this survey data can be carried out next to a deeper analysis of the study.

Table 4 is the analysis of these factors.

As can be seen from, we have selected 10 principal components.

It can be seen from Table 4 that principal component 1 contains A22, A7, A23, A24, A5, A29, A12, A9; principal component 2 contains A2, A1, A3, A11; principal component 3 contains A19 A20, A27, A33, A25; A5, A10; A10, A15, A16, A15; A7, A21, A4; principal component 5 contains A30, A27, A33, A25; A34; principal component 8 contains A28, A26; principal component 9 contains A31, A32; principal component 10 contains A14, A13.

The above-mentioned processing results correspond to the topic, the questionnaire can be divided into the following ten parts:

(1) Principal component 1 indicates the motivating factor of the work content itself, and to some extent shows the importance of training and training. The contribution rate of this factor accounted for $10.461 \%$, also shows that the factors are important. Mainly to include the job more learning opportunities; get more training opportunities.

(2) The main component 2 represents the promotion of incentives, the contribution rate of the factor accounted for $8.791 \%$, mainly including their own ideas and ideas to be implemented; to master and control more resources.

(3) The main component 3 represents the job position factor, the contribution rate of the factor accounted for $7.323 \%$, mainly including the post need to communicate with others coordination; positions have more field opportunities.

(4) The main component 4 represents the welfare benefits of promotion incentives, the contribution rate of this factor accounted for $5.457 \%$, mainly to get more wages and benefits; positions more in line with personal character.

(5) The main component 5 is the spiritual incentive factor, the contribution rate of this factor accounted for $4.998 \%$, mainly to prove to others that their ability to work very strong; access to colleagues recognition and approval.

(6) The main component 6 indicates the resource allocation factor brought by the promotion incentive. The contribution rate of this factor is $4.877 \%$, which mainly includes easy to control others to reduce the intensity of their work; it is easy to solve some problems in life.

(7) The main component 7 represents the material incentive factor, the contribution rate of this factor accounted for $4.508 \%$, mainly to get more bonus income and material incentives; get bonus income. 
Table 4 Rotational component matrix ${ }^{\mathrm{a}}$

\begin{tabular}{|c|c|c|c|c|c|c|c|c|c|c|}
\hline & \multicolumn{10}{|c|}{ component } \\
\hline & 1 & 2 & 3 & 4 & 5 & 6 & 7 & 8 & 9 & 10 \\
\hline A22 & .760 & -.040 & .158 & .162 & .121 & -.062 & .081 & .026 & .040 & .024 \\
\hline A7 & .704 & .053 & .126 & .024 & .084 & .120 & .084 & -.050 & .012 & .064 \\
\hline A23 & .674 & .055 & .103 & .107 & -.043 & .059 & -.021 & .248 & .086 & .016 \\
\hline A24 & .666 & .063 & .057 & .155 & .076 & .115 & -.031 & .036 & -.045 & -.065 \\
\hline A5 & .532 & .468 & .173 & .030 & .137 & -.058 & -.041 & .012 & .064 & .055 \\
\hline A29 & .477 & .283 & .003 & -.106 & .058 & -.225 & .198 & .333 & -.021 & -.213 \\
\hline A12 & .464 & .400 & .272 & .074 & .250 & -.163 & -.051 & .049 & -.053 & .189 \\
\hline A9 & .381 & .371 & .165 & .117 & -.021 & .293 & .078 & -.049 & -.040 & .247 \\
\hline A2 & .134 & .685 & .091 & .231 & .043 & -.032 & .084 & -.150 & -.043 & -.144 \\
\hline A1 & -.026 & -.685 & -.075 & -.160 & -.077 & -.031 & -.180 & .095 & -.054 & $3.416 \mathrm{E}-$ \\
\hline A3 & .018 & .637 & .108 & .100 & -.030 & .327 & .032 & .014 & .184 & .069 \\
\hline A11 & .201 & .543 & .146 & -.210 & .154 & .145 & -.174 & .354 & -.095 & .144 \\
\hline A19 & .199 & .031 & .760 & -.108 & .043 & -.064 & -.058 & .029 & .054 & .009 \\
\hline A18 & .186 & .019 & .701 & .087 & .068 & .112 & .143 & -.004 & .066 & -.126 \\
\hline A17 & .260 & .134 & .668 & .252 & .043 & .116 & .019 & -.087 & .064 & .043 \\
\hline A20 & -.219 & .279 & .570 & .002 & .106 & .039 & .047 & .318 & .042 & .059 \\
\hline A16 & .196 & .255 & .483 & -.165 & .039 & -.400 & .014 & .138 & -.024 & .042 \\
\hline A15 & -.138 & -.258 & -.360 & .007 & -.105 & .273 & .107 & .241 & .351 & -.175 \\
\hline A6 & .104 & .070 & -.026 & .640 & .060 & .096 & .170 & .062 & .027 & -.015 \\
\hline A21 & .270 & .170 & .082 & .541 & .073 & -.058 & -.098 & .153 & -.113 & .028 \\
\hline A4 & .292 & .412 & .071 & .490 & .103 & .278 & .057 & -.212 & .012 & -.021 \\
\hline A30 & .051 & .224 & .198 & .043 & .670 & .041 & .011 & -.147 & .007 & -.023 \\
\hline A27 & .211 & -.062 & -.034 & .090 & .646 & -.171 & .140 & .171 & .183 & -.021 \\
\hline A33 & .131 & -.032 & .050 & .010 & .506 & .082 & .080 & .426 & -.196 & .277 \\
\hline A25 & .058 & .353 & .113 & .395 & .477 & -.003 & -.103 & .215 & .012 & -.022 \\
\hline A8 & .092 & .183 & .057 & -.083 & -.066 & .710 & .179 & .007 & -.090 & -.045 \\
\hline A10 & .115 & .117 & -.009 & .419 & .018 & .607 & .091 & .008 & .094 & .008 \\
\hline A35 & .020 & .171 & -.010 & .198 & -.054 & .100 & .790 & -.106 & .051 & -.047 \\
\hline A34 & .108 & -.003 & .116 & -.060 & .199 & .188 & .680 & .168 & .018 & .185 \\
\hline A28 & .126 & -.271 & .039 & .134 & .086 & -.025 & -.035 & .603 & .071 & -.086 \\
\hline A26 & .380 & .153 & .096 & .306 & .000 & -.068 & .262 & .441 & .164 & -.098 \\
\hline A31 & .055 & .155 & .174 & .090 & -.018 & .000 & .177 & .027 & .677 & .065 \\
\hline A32 & .046 & -.069 & .008 & -.318 & .340 & -.047 & -.248 & .000 & .589 & -.030 \\
\hline A14 & .038 & .010 & .029 & .049 & -.056 & -.003 & -.106 & .096 & .009 & -.788 \\
\hline A13 & .275 & .123 & .006 & .131 & -.166 & -.241 & -.159 & .244 & .283 & .442 \\
\hline
\end{tabular}

Extraction method: principal component analysis

Rotation method: orthogonal rotation method with Kaiser standardization

a. The rotation converges after the 13 iteration

Source: the author draws on the results of the survey

(8)The main component 8 is the spirit of the incentive to bring personal intuitive experience factors, the contribution rate of this factor accounted for $4.409 \%$, mainly to get the object of praise; get a higher professional titles or title.

(9) The main component 9 is the spirit of the incentive to bring the inner feelings of factors, the contribution rate of the factors accounted for 3.512\%, mainly to avoid being looked down upon by colleagues; do not have the heart to see others busy and do nothing.

(10) The main component 10 indicates that the position is matched with the individual, the contribution rate of the factor is $3.462 \%$, mainly including the position more in line with their hobbies or specialty; post and more in line with their own professional. 
From the principal component analysis can be seen, work motivation and promotion incentive dimension is relatively important, their share of the contribution rate is relatively high. On the whole, the most important incentive dimension of job content, that is to say the most important work incentive indicators.

\section{Research conclusions and related countermeasures}

To sum up, the three kinds of incentive dimensions demonstrated in this paper can be seen from the principal component analysis, which is the most important dimension of the work content incentive, that is, the importance of the indicators in the work content incentive is the importance of the problem. Thus, we can use these three kinds of incentive dimensions which indicators are relatively important, to encourage public security police to make recommendations. Suggestions are as follows:

\subsection{Promotion motivation}

Promotion is one of the important goals pursued by all civilian police career. From the survey results, the promotion of the incentive dimension is relatively important. First, in promotion, Hainan Province, the police to establish an open and transparent promotion mechanism, from the survey data can be seen in Hainan Province, the vast majority of police in 45 Under the age of the young people should be more opportunities for development, and these can be through the competition system and job tenure system, so that before and after the post, before and after the service can be the survival of the fittest, can be on the next. Second, broaden the promotion channels, increase the level of space, the appropriate provision of wages and benefits to these people. Although "the Civil Servant Law of the People's Republic of China" stipulates that the civil service level is fifteen, there are only six levels of civil servants. While 92\% of our civil servants are below the rank, job promotion is extremely difficult. From the research data can be seen, after the promotion may be more wages and benefits, is conducive to improving the enthusiasm of the police work.Third, to promote civil service exchanges. According to the needs of the work or the personal wishes of the civil servants, through the statutory form, in the administrative organs to change the civil service positions, or civil servants transferred to the executive office, or the administrative organs of the staff transferred to the executive office[2].

\subsection{Work content motivation}

Work content motivation refers to the distribution of work content to do the staff to meet the preferences and hobbies; work is challenging, give full play to the potential of workers. First, through the work of satisfaction, that is, through the changes in the content of the work of the police and their work behavior recognition and rewards, so that the police have a sense of satisfaction with their work.. Well-known management behaviorologist Herzberg proposed a two-factor theory that divides the factors that affect employee work into two categories: health factors and incentives. He believes that health care can only solve the employee's discontent, and can not have a great impact on its enthusiasm. Second, through training and development incentives, the public sector has planned activities to enable employees to acquire or improve their work-related knowledge, skills, competencies, attitudes, motivations and behaviors, and to promote employee performance through these activities Employee behavior is consistent with the strategic objectives of the public sector. From the survey data can be seen, Hainan Province, police attach great importance to the role of training, through training, so that they have too much learning opportunities, or skills. Which to some extent can inspire the police to work hard. Third, through the incentive to strengthen the role of internal incentives. From the above survey data can be seen, most of the civilian police in Hainan Province want to play a better personal value, only their strong sense of responsibility in order to better serve the people, and finally to better achieve personal values.

\subsection{Material motivation and spiritual motivation}

We want to promote the principle of material motivation and spiritual motivation, to take a 
variety of incentives. First, establish a flexible remuneration system, highlight and give full play to the role of income distribution incentives, to reflect the fair, just and open. Survey data show that if their own work is recognized, but also to promote their own hard work. Second, Pay attention to the combination of spiritual reward and material reward, spiritual reward in addition to the honorary title, you can also have such as certificates, medals, trophies and other kind of honor awards. In fact, the research data show that the importance of material and spiritual problems is relatively weak, In addition to the higher political literacy of high-level police, in particular, to the spirit of the main incentive, from the work itself to experience the meaning of work and the responsibility given.

\section{Acknowledgements}

The authors are particularly grateful to Professor Yanqing Xu's careful guidance. This paper is financed by the Natural science Foundation Project(71704041).

\section{References}

[1] Suning Peng. Analysis on the Demand and Path of Public Security Police's Professional Ability Promotion [J]. Public Security Research, 2012,05: 70-73 + 83.

[2] Fang Shu, Keliang Wang. Civil service system tutorial [M]. Beijing: Renmin University of China Press. 2011.

[3] Shipley D, Kiely J. Industrial Salesforce Motivation and Herzberg's Dual Factor Theory: A UK Perspective. Journal Of Personal Selling \& Sales Management [serial on the Internet]. (1986, May); 6(1): 9.

[4] Li' an Zhou. Administrative contract system [J]. Society, 2014,(06):1-38.

[5] Qianjin Ma.The Two-factor Theory and the Occupational Incentive Mechanism of Police [J].Journal of Wuhan Public Security College, 2015,02: 21-26. 